\title{
Electric utility 4.0: Trends and challenges towards process safety and environmental protection
}

\author{
Lara B. Liboni $^{\mathrm{a}, *}$, Luisa H.B. Liboni ${ }^{\mathrm{b}, \mathrm{c}}$, Luciana O. Cezarino ${ }^{\mathrm{d}}$ \\ a School of Economics, Business Administration and Accounting at Ribeirao Preto, University of Sao Paulo, USP, Brazil \\ ${ }^{\mathrm{b}}$ Department of Electrical and Computer Engineering, Federal Institute of Education, Science and Technology of São Paulo, Sertãozinho, Brazil \\ ${ }^{c}$ Department of Electrical and Computer Engineering, University of São Paulo, São Carlos, Brazil \\ ${ }^{\mathrm{d}}$ Faculty of Management and Business, Federal University of Uberlandia, Brazil
}

\section{A R T I C L E I N F O}

Article history:

Received 15 February 2018

Received in revised form 24 May 2018

Accepted 27 May 2018

Available online 30 May 2018

\section{Keywords:}

Environmental protection

Process safety

Electric utility

Electric system

Industry 4.0

Soft System Methodology (SSM)

Dynamic capabilities

\begin{abstract}
A B S T R A C T
The traditional manufacturing business model is changing for new emerging models. Many changes are related to the industry 4.0 challenge and among them there is a concern regarding how industries will meet the objectives of sustainable operations, especially on that of environmental protection and process safety. Some industries are making great efforts to get aligned with the industry 4.0 paradigm, and for the Electric System Industry, it is no different. Because of its strategic and environmental importance, the electric system industry must be investigated. In this article we used qualitative research based on a systemic approach, using the Soft System Methodology (SSM) to address the challenges brought by the industry 4.0 paradigm in the electric system industry in Brazil, focusing on the topic of environmental protection and process safety. Moreover, we point out important capabilities needed by these companies to keep up with the new industrial revolution. Results from the SSM have exposed important management gaps and hence have shown new possible management models that can contribute to the modernization of the electric utilities in Brazil, making these industries more sustainable. In fact, it is imperative for companies to detail the organizational capabilities they will need to thrive in the business process. Therefore, we conclude the paper by indicating the three main dynamic capabilities that have emerged: new policies to enable innovation, bureaucracy reduction, and investments in education.
\end{abstract}

(C) 2018 Published by Elsevier B.V. on behalf of Institution of Chemical Engineers.

\section{Introduction}

A digital transformation is now underway in the industrial ecosystem. Industries are enhancing their digital functionality in manufacturing processes and operations as well as in their portfolios, enabling innovative digital and data-based services (Zhong et al., 2017).

The industry 4.0 term stands for the fourth industrial revolution and generates impact on all industries around the world (Stock and Seliger, 2016; Prause and Atari, 2017). It is a shorthand name to describe the fast changes in the value chain of industries, which are encouraged by the concepts of the industrial internet and digital factory. The Industry 4.0 paradigm encompasses multi-dimensional aspects of business operations and brings improvements in industrial processes, as material usage, circular economy, and supply and value chain (Strandhagen et al., 2017a,b). The application of Industry 4.0 and related concepts and

\footnotetext{
* Corresponding author.

E-mail address: laraliboni@usp.br (L.B. Liboni).
}

technologies is part of an ongoing discussion, which has effects throughout the entire industry.

Past revolutions in manufacturing were focused on the automation of single machines or processes. Now, the new revolution promises to generate analyses and communicate data to improve value on products and services in an optimized and intelligent way (Schwab, 2017). Therefore, information from lower levels of automation, single machines, process variables, and production logs must be condensed, communicated and learned flawlessly and rapidly. These characteristics set the new global picture of value creation and the role of the new industry (Geissbauer et al., 2016).

We can set the scene of the industry 4.0 framework. This framework is composed primarily of the core capability of Data $\mathcal{E}$ Analytics, where digitization of data from production processes and services lead to the integration of vertical and horizontal value chains (Marques et al., 2017). Moreover, this capability enables the design of new digital business models and the greater access of customers to services. One can observe that to achieve such paradigms, the use of contributing technologies is paramount. We can pinpoint different cutting-edge technologies such as cloud computing, Internet of Things (IoT) platform, advanced human-machine interfaces, 
augmented reality, mobile devices, smart sensors, 3D printing, authentication \& fraud detection, customer interaction, advanced algorithms for data and big data analysis, artificial intelligence and machine learning. (Baccarelli et al., 2017; Wan et al., 2016, Monostori et al., 2016; Li et al., 2017). It is no accident that the estimates of investments made by industries in such technologies are around US\$ 907 bn (Geissbauer et al., 2016).

For Shim et al. (2017) the new automation can help increase the capacity for product customization, mass production, flexibility, and quality of products (Mourtzis et al., 2016; Lee et al., 2014), attending different needs and desires from customers.

Besides all these changes, this industrial revolution also represents a desire to respond to present issues related to the principles of sustainable development (Bakkari and Khatory, 2017). It is clear that environmental concerns from the industry impact production innovations, strategies, and processes (Sarkis and Zhu, 2018).

As pointed out in Geissbauer et al. (2016), some challenges such as data security, human control, energy efficiency, and pollution are concerns that are very prominent in diverse industrial sectors. With the advent of smart production systems, these concerns will have to be revisited and debated in order to fit the new market dynamics into sustainable goals.

Sustainability is a crucial value for all industries to develop processes, products, or services (Gregori et al., 2017). Industry 4.0 can provide opportunities for the implementation of sustainable manufacturing (Stock and Seliger, 2016). Standard mass customization can be excellent for old industrial purposes (Shim et al., 2017) but when it comes to sustainable operations (Kleindorfer et al., 2005) and sustainable supply chain management (Seuring and Müller, 2008) there are other activities that poses several implications on economic, environmental, and social aspects regarded to the Triple Bottom Line (TBL) of sustainable value creation (Kiel et al., 2017).

In this case, managers need to think about how the industry 4.0 can meet the objectives of sustainable operations, especially about environmental protection and process safety. Industries of the electric system are composed of a complex network of power plants, transmission, and distribution wires and have a high environmental impact. As an example, according to REN21 Report (2016) hydropower is produced in 150 countries. China is the largest hydroelectricity producer, with 920 TWh of production in 2013 , representing $16.9 \%$ of the domestic electricity use. The construction of a hydropower plant can be a planned environmental intervention, but it always has a high impact on the ecosystem. Once working, the project produces no direct waste and has a considerably lower output level of greenhouse gases than fossil fuel powered energy plants (REN21 Report, 2016). Changes focused on process safety will reduce the risk of water shortage and maintain efficient population access. Furthermore, changes in environmental protection can protect surrounding areas of electrical stations and the nearby populations.

Not only power generation has an important role in the environment but also power transmission and distribution. We can pinpoint the effects on ecosystems, animals, and plants that result from the air, water, waste, and landscape impacts these networks cause. Moreover, faults or transient events can directly affect the safety of employees and communities (EPA United States Environmental Protection Agency, 2017).

Previous works have mentioned relevant shifts related to manufacture industries (Zheng et al., 2018; Wang et al., 2016; Kang et al., 2016). However, in the case of utility companies, few papers focus on its systemic impacts (Kleineidam et al., 2017; Shrouf et al., 2014) and none provided management solutions for striking such changes. In this paper, we shall discuss the inevitable trend regarding management practices that electric utility companies will face within the paradigms of industry 4.0. Specifically, an electric utility is a company in the electric system that owns and operates equipment and facilities for the generation, transmission, and distribution of electric energy. Therefore, electric utilities are industries that have a great impact on the environment and is, at the same time, a strategic industry for a country (Ralff-Douglas and Zafar, 2015). The term industry designates the set of activities that manipulate raw materials for the production of consumer goods. In the case of the electricity industry, electricity is a product used indirectly to produce light, movement, heat or any other energy transformation.

It is crucial to associate environmental protection and process safety to outcomes of a properly designed management system for utility industries. Meanwhile, we ask what are the challenges, within the ongoing industry 4.0 changes, that electric system utilities have to address to guarantee a more sustainable environment and safer processes? For that, the Soft System Methodology (Checkland, 1981) was chosen as an adequate methodology, since it is useful to solve complex and ambiguous problems. An interview with a specialist in the electric system industry dynamics will provide qualitative data.

\section{Sustainable operations: environmental protection and process safety}

One of the main scopes of data digitization is achieving more efficient operations (Gregori et al., 2017). Digitization represents a real opportunity towards value-oriented sustainable activities through several conditions, especially regarding environmental protection (EP) and process safety (PS). Associating both themes, Industry 4.0 can improve risk assessment and minimize oscillations throughout industrial processes with benefits to the material, products, waste and energy management.

From process safety dynamics, one can state that uncertainty is inherent and unavoidable in operations since it belongs to the physical variability of a system response (Markowski et al., 2009). Process safety is the common global language used to communicate the strategies of hazard identification and analysis, risk assessment and evaluation, safety measures, and safer critical decision-making. The common objective of any safety assessment and risk analysis technique is to assure that a process or a system is designed and operated to meet "accepted risk" or a "threshold" criterion (Ferdous et al., 2013).

Industry 4.0 requires standardization (Müller et al., 2018) and stability of processes within and among companies. Process safety encloses data management to predict the reliability of technological systems over a given period. It is an integral part of process development and manufacturing rather than an "add-on" to the process (De Rademaeker et al., 2014). Process digitalization also means more control on management operations, reducing errors, gargles, lack of components, or unestablished production rhythm.

For example, Gabriel and Pessel (2016) points out that smarter logistics are responsible for reducing transport processes as well as unnecessary material flows. Delivery mistakes, needless awaiting times, and turned-back goods can also be minimized by data transparency throughout the entire supply chain. Additive manufacturing, which is one of the core technologies in the Industry 4.0 era, and physical transportation procedures are decreased, especially for spare parts (Oettmeier and Hofmann, 2017). In the same vein, transparency in the intra/inter-firm logistics (Oesterreich and Teuteberg, 2016) can be help increase process stability and reduce risks of ruptures.

Besides the enhanced process safety management, in general, Industry 4.0 enables the reduction of greenhouse gas emissions by data-centered and traceable carbon footprint analyses (Peukert et al., 2015) of the value chain or networks (Herrmann et al., 2014). In specific terms, strategic opportunities in environmental pro- 
tection can be visualized in three main aspects: materials and products, waste, and resource management.

Material and product management emphasize healthier and less demanding products and raw materials (Waibel et al., 2017). Smart factories increase their resource efficiency by using the pull principle, i.e., an increased demand orientation that enables load balancing. It means that raw materials or semi-finished materials are requested on demand by automatically ordering materials and parts from their suppliers (Wan et al., 2016; Geissdoerfer et al., 2017). Therefore, a decentralized production is made possible, where the production is close to where products are consumed (Müller et al., 2017).

Regarding waste management, robots and machine learning will revolutionize waste sorting and product (dis)assembly systems. The use of apps and sensors supports and improves waste separation and collection practices (Vrancken, 2018). Digital recognition of volume, type, and correct destination will facilitate more responsible disposal.

Moreover, industry 4.0 paradigm also encompasses energy efficiency and reliability as its core component. More energy efficient and reliable facilities are crucial to lead the way to production efficiency. Smart manufacturing companies can plan energy-intensive tasks when there is a natural overproduction of energy since smart meters are directly connected to power plants, decentralized solar, and wind production. Furthermore, other surrounding companies can use the energy surplus (Waibel et al., 2017).

The smart production also facilitates the supply chain management, and as a consequence, the ability of recycling, reusing and remanufacturing. Circular economy or lifecycle initiatives emphasize cycling of materials by integrating technology and closing the material loops which may contribute to more sustainable business models (Murray et al., 2017; Vrancken, 2018). The greater the knowledge about the vertical value chain, the greater the aptitude of the company to thrive in a completely new and competitive market. This knowledge also impacts the horizontal integration of the value chain since technologies to track and analyze products and services affects suppliers and customers operation and the relationship between these players.

Sarkis and Zhu, 2018 outline the industry 4.0 paradigm: (1) horizontal integration across the entire value creation network, (2) end-to-end engineering across the entire product lifecycle, and (3) vertical integration and networked manufacturing systems that fits the necessity to include closed value creation networks, reuse resources and tools, and retrofit machines (Stock and Seliger, 2016). Manufacturing processes, usage back to design (Glavič and Lukman, 2007), can be improved through direct data interconnection closing loops throughout the network and leading to a cleaner and systemic material management.

Smart production systems will require massive data centers to process and support their network needs. Therefore, one of the biggest challenges of this rapid transformation for diverse industrial sectors is in its people (Geissbauer et al., 2016). Another challenge is in the still missing IT knowledge among the workforce. Therefore, workers in every field of the smart factory need to have solid IT skills. Training will be more important than ever to teach specific skills and generate acceptance among the employees for new technologies. Different job profiles with novel expertise for programming and software development are expected to occur. Employees will need to surpass the digital qualification barrier in order to undertake digital process and services. Therefore, a great part of the investment in the industry 4.0 is focused on training employees and creating methods and pathways for a structured change in the organizational aspect of production and services (Geissbauer et al., 2016).

Finally, in the smart industry, the whole load of data and communication must be handled properly in order to ensure that the

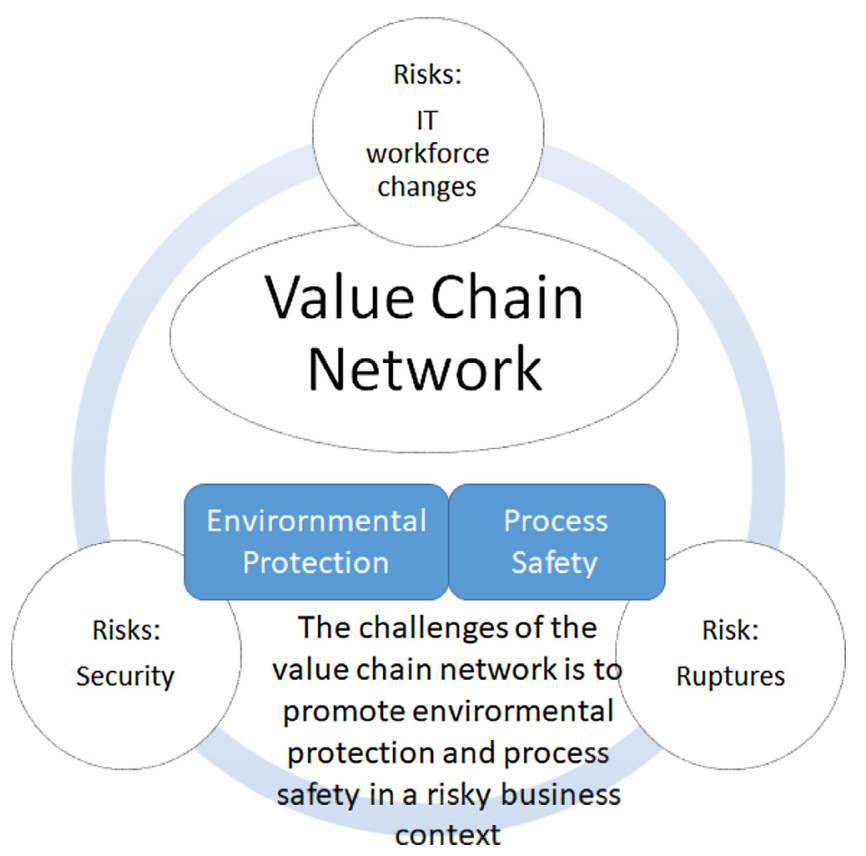

Fig. 1. Challenges for EP and PS inside the industry 4.0 paradigm.

investment will not compromise the integrity of important and confidential information. IT safekeeping is one of the most relevant areas of smart production systems in which frauds, spying, terrorism, hackers, and threats are addressed when data is stored in cloud providers.

For Müller et al. (2018), new business models emerge through data-driven products and services, including increased customer orientation and service-based business models enabled by data transparency. Therefore, the implementation of the industry 4.0 paradigm requires focusing value network on two major challenges: environmental protection (waste, resource and materials/products management) and process safety (stability and transparency).

Fig. 1 shows the dynamics of environmental protection and process safety in the industry 4.0 paradigm.

Focusing on these two challenges - environmental protection and process safety - the implementation of the industry 4.0 paradigm mobilize important changes in the organizational structure, strategy, and practices. In summary, organizational changes can be seen in products, human resources, processes, equipment, and decision-making (Table 1 and Fig. 2).

However, all these practices regarding industry 4.0 are common for manufacturing industries. We need to extend these trends to the mass services value chain. Electric utility companies are critical to other industries and even relevant to offer population safety and to protect the environment. In this way, we explore how this specific industry needs to develop management practices to become smarter, considering the environmental, economic, technological, and regulatory context.

\section{Methods}

This paper is an exploratory research (Selltiz, 1974) that uses an in-depth interview to perform an SSM (Checkland, 1981). The methodology consists in constructing knowledge between the real world and the systemic world, making the thinker oscillates between ideal solutions and everyday life problems. Soft problems are essentially ambiguous, multifaceted, and complex and seem too broad to be managed (Zexian and Xuhui, 2010). For Checkland (2000), the process of learning by relating experience 
Table 1

Trends and expected developments for the value creation factors in the Industry 4.0 industries.

\begin{tabular}{|c|c|}
\hline Equipment & $\begin{array}{l}\text { The manufacturing equipment will be characterized by the application of highly automated machine tools and robots. The } \\
\text { equipment will be able to flexibly adapt to changes in the other value creation factors, e.g., the robots will be working together } \\
\text { collaboratively with the workers on joint tasks. }\end{array}$ \\
\hline Human & $\begin{array}{l}\text { The current jobs in manufacturing are facing a high risk of being automated to a large extent. The numbers of workers will thus } \\
\text { decrease. The remaining manufacturing jobs will contain more knowledge work as well as more short-term and hard-to-plan } \\
\text { tasks. The workers increasingly have to monitor the automated equipment, are being integrated into decentralized } \\
\text { decision-making, and are participating in engineering activities as part of the end-to-end engineering. }\end{array}$ \\
\hline Structure & $\begin{array}{l}\text { The increasing organizational complexity in the manufacturing system cannot be managed by a central instance from a } \\
\text { certain point on. Decision making will thus be shifted away from a central instance towards decentralized instances. The } \\
\text { decentralized instances will autonomously consider local information for the decision- making. The decision itself will be } \\
\text { taken by the workers or by the equipment using methods from the field of artificial intelligence. }\end{array}$ \\
\hline Process & $\begin{array}{l}\text { Additive manufacturing technologies also known as 3D printing will be increasingly deployed in value creation processes } \\
\text { since the costs of additive manufacturing have been rapidly dropping during the last years by simultaneously increasing } \\
\text { regarding speed and precision. This allows designing more complex, stronger, and more lightweight geometries as well as the } \\
\text { application of additive manufacturing to higher quantities and larger scales of the product. }\end{array}$ \\
\hline Product & $\begin{array}{l}\text { The products will be manufactured in batch size one according to the individual requirements of the customer. This mass } \\
\text { customization of the product integrates the customer as early as possible in the value chain. The physical product will also be } \\
\text { combined with new services offering functionality and access rather than product ownership to the customer as part of new } \\
\text { business models. }\end{array}$ \\
\hline
\end{tabular}

Source: Stock and Seliger (2016)

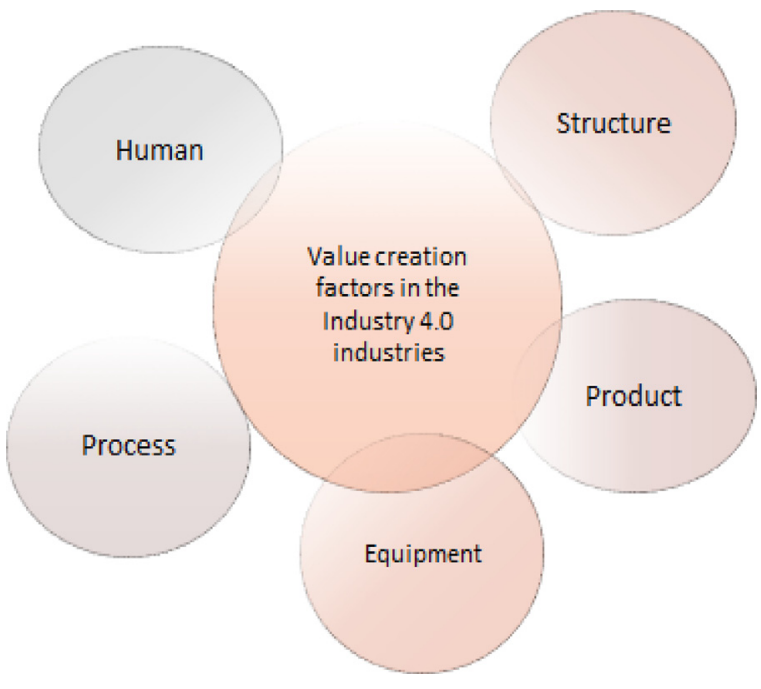

Fig. 2. Value creation factors in the Industry 4.0 industries.

to ideas is always both rich and confusing. However, as long as the interaction between the rhetoric and the experienced 'reality' is the subject of conscious and continual reflection, there is a good chance of recognizing and pinning down the learning which has occurred. The formalization of systemic thinking in the Soft Systems Methodology, when decisions need to be made in poor-information contexts, can help the decision-making process to be more effective (Cezarino et al., 2016; Liboni et al., 2015; Georgiou, 2008). Fig. 3 illustrates the seven steps of SSM.

At the end of the SSM, we shall point out the range of management possibilities for how the electric utilities can move forward in becoming smart, within environmental demands and safety requirements.

\section{Results}

\subsection{Step 1-problem situation}

Manufacturing industries within the smart industry context are taking energy efficiency as a new paradigm and also issues regarding electricity (Shrouf et al., 2014). Not only industries are dependable on electricity, but also hospitals, data centers, airports and essential public services are also dependent on electricity to provide human safety. An interruption or diminished quality of the electricity could lead to chaotic consequences. Moreover, all parts of the electric system can have a direct impact on the environment. Therefore, we can state that modern management practices that increase the efficiency of electric energy generation, transmission, and distribution will be needed for the next generation of electric utilities. This new practices should, therefore, help transform the electric grid and the electric utility companies in a smart grid and industry, inserting them in the paradigms of Industry 4.0.

The benefits from this transformation are straightforward: customers would have better-quality electricity. Equipment in small-business, residences, and large industries would provide information that shows how much electricity is being used and how, which would enable costs reduction. Electricity providers would be able to fix problems more quickly and predict them up ahead time. With this information, utilities would also better manage the distributed generation, optimizing investments in different types of generation sources and infrastructure location. Finally, users and providers would become partners in making the electric system not only more reliable and efficient but also more environmentally aware. Therefore, the overall efficiency of the power system would improve, and long-term investment on large electric power generation plants could be diminished. More electricity could arise from distributed generation, such as solar, biofuel, and wind power plants.

However, by looking to the electric utility sector, in many countries, we can notice that this sector is lagging behind the manufacturing industries in the modernization of production and use of industry 4.0 paradigms. This is not different in Brazil, where the electric system industries are giving their first steps toward a smart production. It is enough to analyze auto industries to notice this lagging, where intelligent cars are produced within a smart framework, with artificial intelligence assisting all the production steps. Another example is the food industry, which is being modernized and creating value from smart deliveries to gourmet food handling, where information on customers preferences are driving value to all the production and supply chain. First movers on the smart industry paradigms are always in the manufacturing industries, where the Internet of Thing (IoT) have been playing an important role in the modernization process.

Why is this lagging persistent? Why are the electric utility companies in Brazil lagging behind? Some particular aspects of this sector can be related to this lagging. We shall detail these aspects in Step 2. 


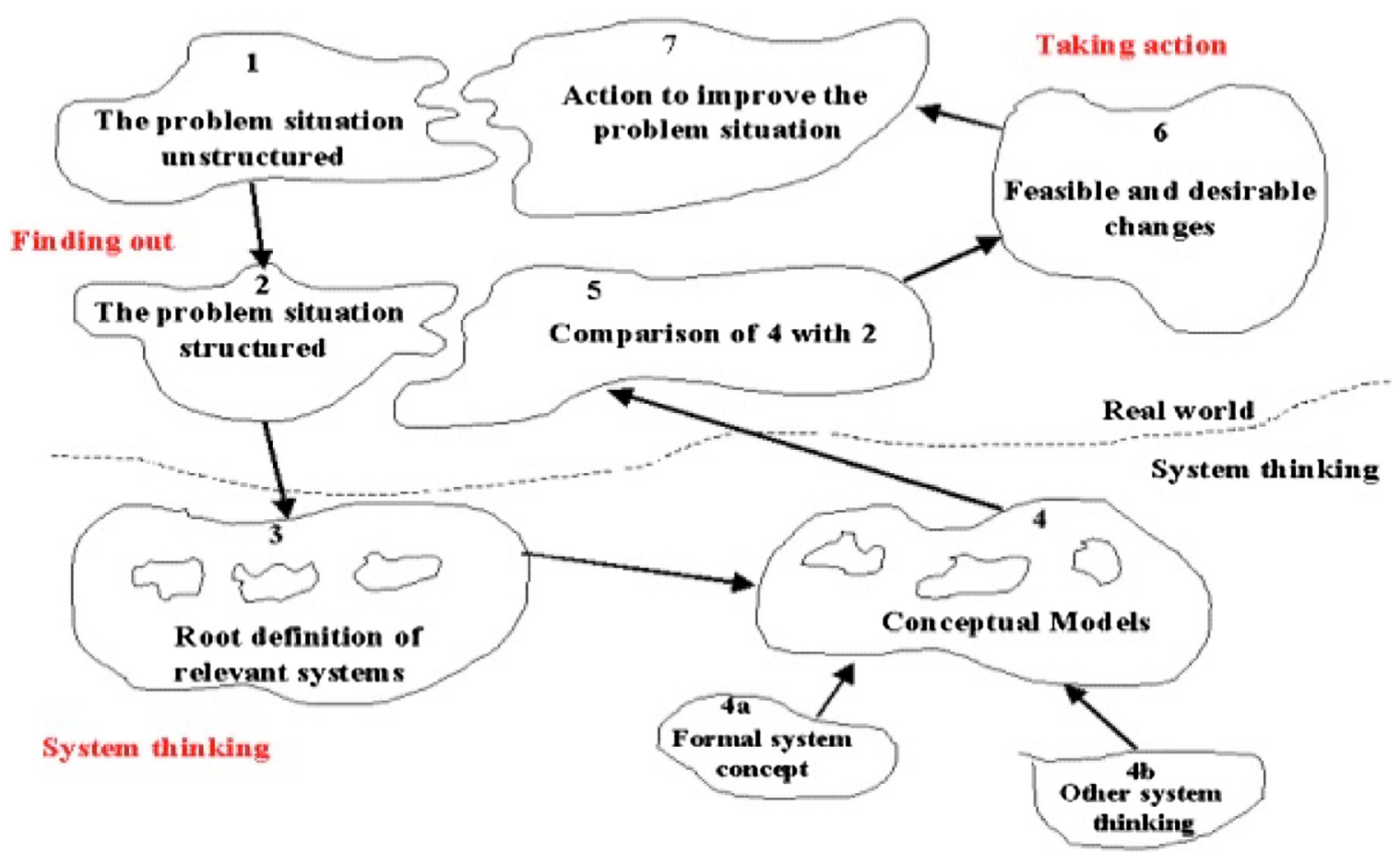

Source: Adapted from Checkland (1981)

Fig. 3. SSM Steps.

\subsection{Step 2-structured problem situation}

The complex electric system is a very particular industry. A relevant point to be mentioned about the production and consumption of electricity is that, unlike other grid systems such as sanitation and gas, electricity cannot be stored in an economically viable way. This implies in the need for a constant equilibrium between supply and demand. In other words, all the energy consumed must be produced instantaneously, and when there are imbalances, even for fractions of minutes, the whole system runs the risk of cascading shutdowns, the so-called "blackouts."

Regulation is another important aspect of basic mass utilities, such as electric utilities. Companies have to respect regulation policies regarding technical solutions from generation, transmission, distribution, and commercialization. Regulations also act upon economic aspects, such as commercial rates, policies in the life cycle of assets, and research and development projects made by the companies. Another important aspect in this sector is the strict environmental policies ranging from generation to distribution. In Brazil, the commercialization of electric energy is made with the participation of intermediate agents between utilities and final customers.

Notwithstanding, information from customers is a very delicate aspect as well. In manufacturing industries, one can interview clients or gather information about a particular customer preference from previous productions or sale experiences. In the electric utility context, information on how people are using electricity is also a security issue since data can reveal people's habits and therefore can cause privacy concerns. The fears about utilities becoming smart are rising at the same pace that the pressure for modernization is rising (Weissman, 2011). Are the smart meters safe? Will bills be placed correctly? Is it safe to be exposed to such a powerful wireless equipment (that transmits information to the utility company)?

Another important aspect regarding the Brazilian electric market is in the purchasing power of customers. The majority of final-use customers are sometimes not willing to invest in new equipment, maybe by misunderstanding the benefits of doing it or by financial constraints.

Now and in the next few decades, the energy sector is expected to meet increasing demand for energy while reducing its greenhouse gas emissions. The pillars to achieve this goal are to improve the efficiency of energy production, transmission, and distribution and to increase the use of renewable energy sources. Brazil has an immense potential for the use of the so-called bioenergy generation.

All these aspects and mistrusts contribute to the striking differences of where manufacturing industries and electric utilities are ranked in the smart industry concept.

Therefore, the great challenge to help utilities to progress is to seek management solutions that consider environmental, economic, technological, and regulatory interests and constraints.

\subsection{Step 3-formulation of essential definitions}

In the third step of SSM, we formulate the essential definitions regarding the Brazilian electric system. Fig. 4 shows a picture of the electric system in Brazil.

Fig. 5 shows the input-output process in the electric system. The Generation (Power Source) is where the electricity is produced. Electricity can be produced by some different generation sources. Hydropower generation is the main source of electricity generation in Brazil. The wind energy is also an important source of electricity generation in Brazil, as well as the cogeneration from biomass.

As in any electric system, the high-voltage transmission lines are where electricity is carried over the bulk electric grid, a network of high-voltage transmission lines that connect power plants to substations and link the electric system. Transmission lines carry electricity from generation facilities to the places where electricity is used.

The substations are critical switching points in the electric system, connecting transmission systems to distribution systems. Substations use transformers to lower the electric voltage. The dis- 


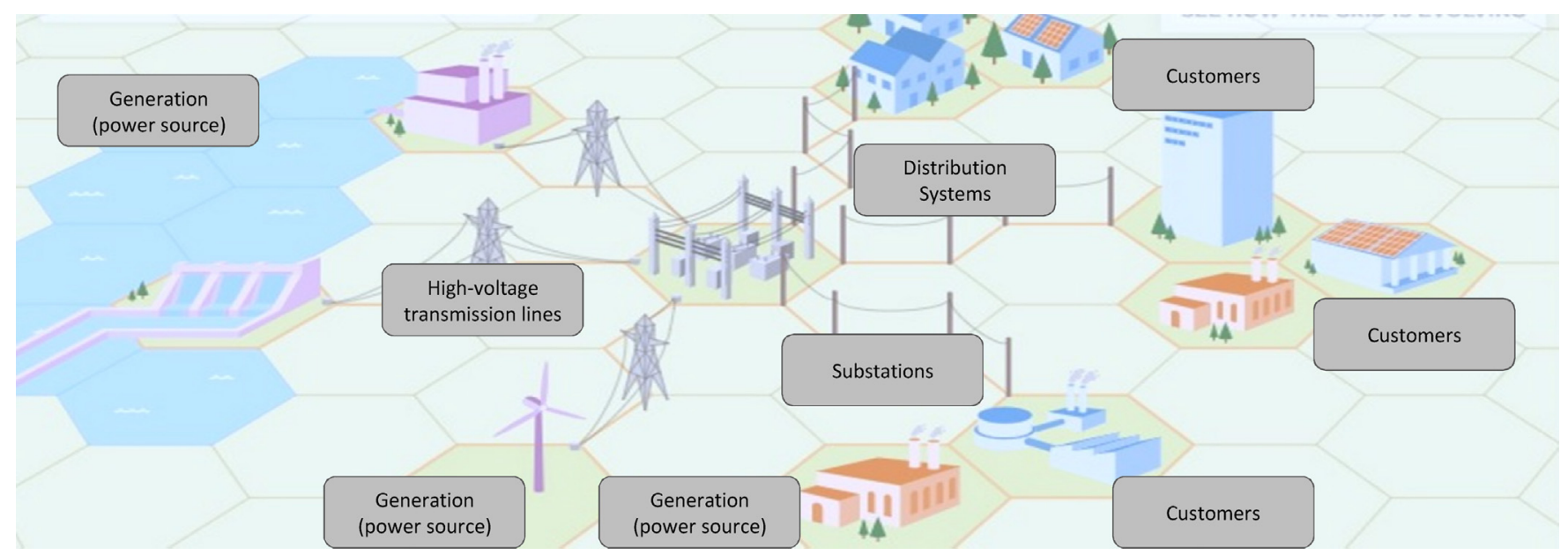

Fig. 4. The electric system in Brazil.

Source: Adapted from the American Association for Environmental Protection - AAEP

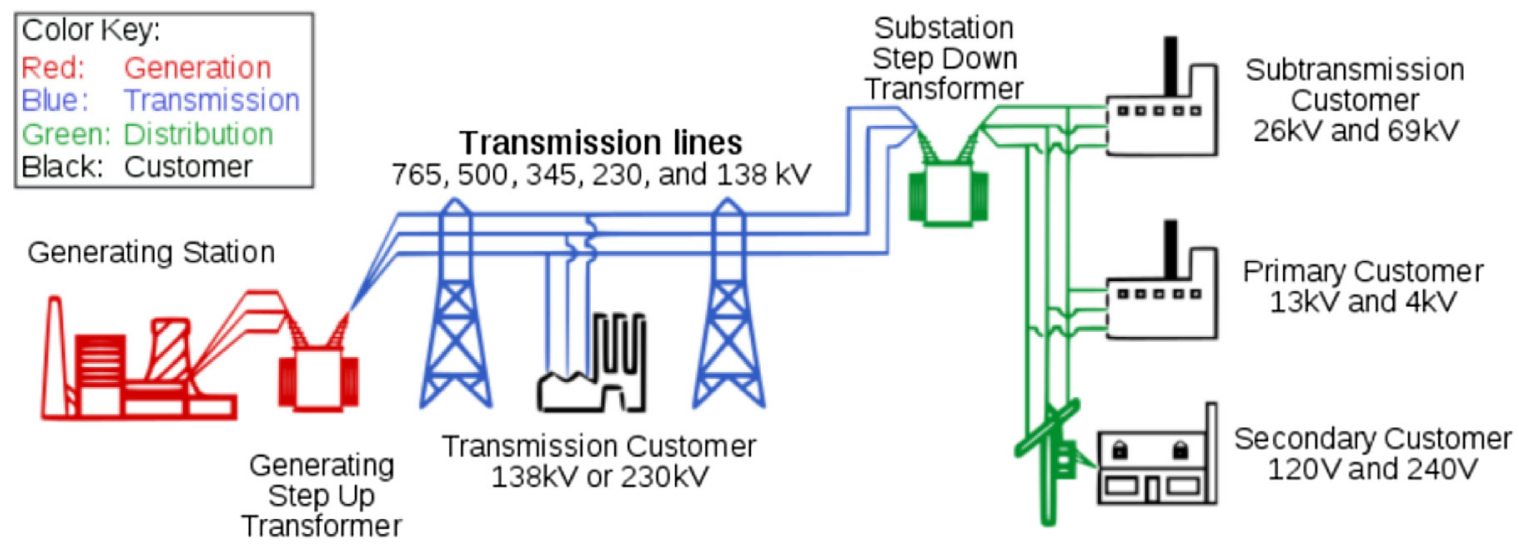

Fig. 5. Simplified diagram of electricity distribution.

Source: United States Department of Energy (2008)

tribution systems link the transmission system to lower-voltage electricity users. They are the most commonly seen along roadsides, carrying electricity to homes and businesses,

The root definition of the structured problem can be described in Fig. 6. The system is supposed to transform resources by using the infrastructure of the electric system and output electricity to customers in a smart and efficient way (smart utility) through the stakeholders of the electric industry.

Brazil follows this conventional structure, where the generation is constituted, in its hydroelectric, thermoelectric, and nuclear power plants, providing consumer units through the so-called National Interconnected System (SIN), which is shown in Fig. 7, managed by the National Electric System Operator (ONS). The system arregendment and sizing is based on the planning report for distribution of loads, issued by the Institute of Electrical and Electronics Engineers (IEEE) in 1991 (Feeders, 1991).

According to Grzeidak et al. (2011), the centralized generation still remains as the fundamental characteristic of any electric system, but the insertion of new generating elements, such as distributed generation, will increase the complexity of the systems. In the case of Brazil, such scenario has as an additional element of complexity: the dimension of the SIN. However, this characteristic also highlights the research potential that scientists and engineers have in developing technology and new management solutions to the complex Brazilian electric system. Hence, with this physical dimension, the use of automation and information technology and algorithms of data processing throughout the system is already a necessity.

According to the Energy Research Company (EPE), the consumption of electricity in the country could grow at an average rate of 4.3\% in the next ten years (Energética Empresa de Pesquisa, 2012). The National Agency of Electric Energy (ANEEL) has the role of regulating the electric-system industry, from generation to the final delivery of electricity.

Table 2 brings the CATWOE, in which we describe the root definitions of all aspects of the 'root purpose' of the system.

\subsection{Step 4 - elaboration of conceptual/ideal models}

Utilities should leverage available technology to optimize assets, increase safety, control the grid, and keep the lights on. Therefore, information management, asset maintenance, and remote diagnostics allow security and better services for the customers. All these aspects result in the well-known smart grid concept (Young et al., 2016). If we were to translate the industry 4.0 paradigm to the specific case of the electric utilities, it would mean having interconnectivity of circuit breakers and sensors through the IoT and information connectivity to monitor, optimize, and control the electric system.

The IoT is a suite of technologies and processes that empower devices of all types with the ability to communicate information and their health status to other systems. Therefore, IoT can improve 


\section{Transformation}

\section{Chasing smart production}

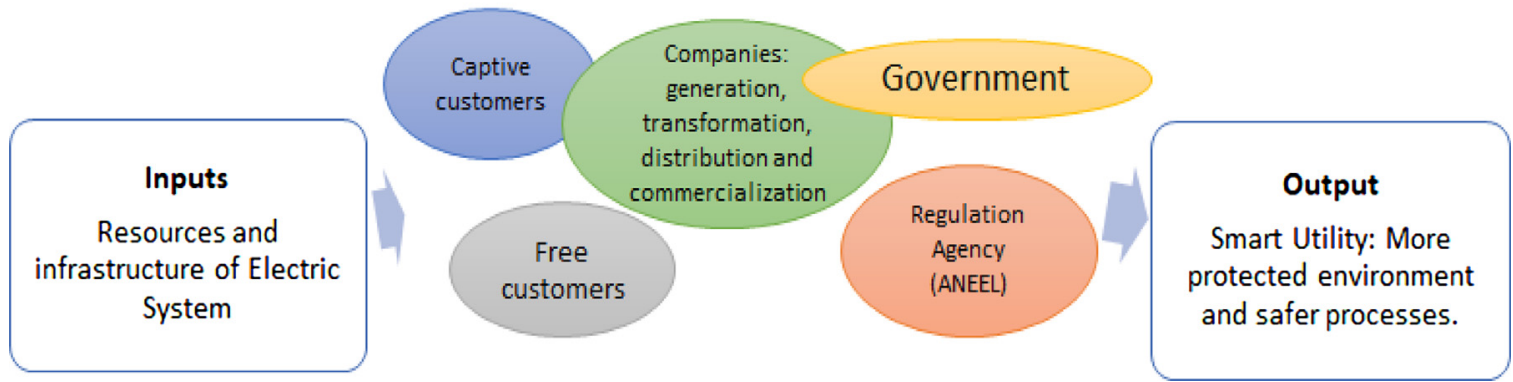

Fig. 6. Root Definition of the Structured Problem.

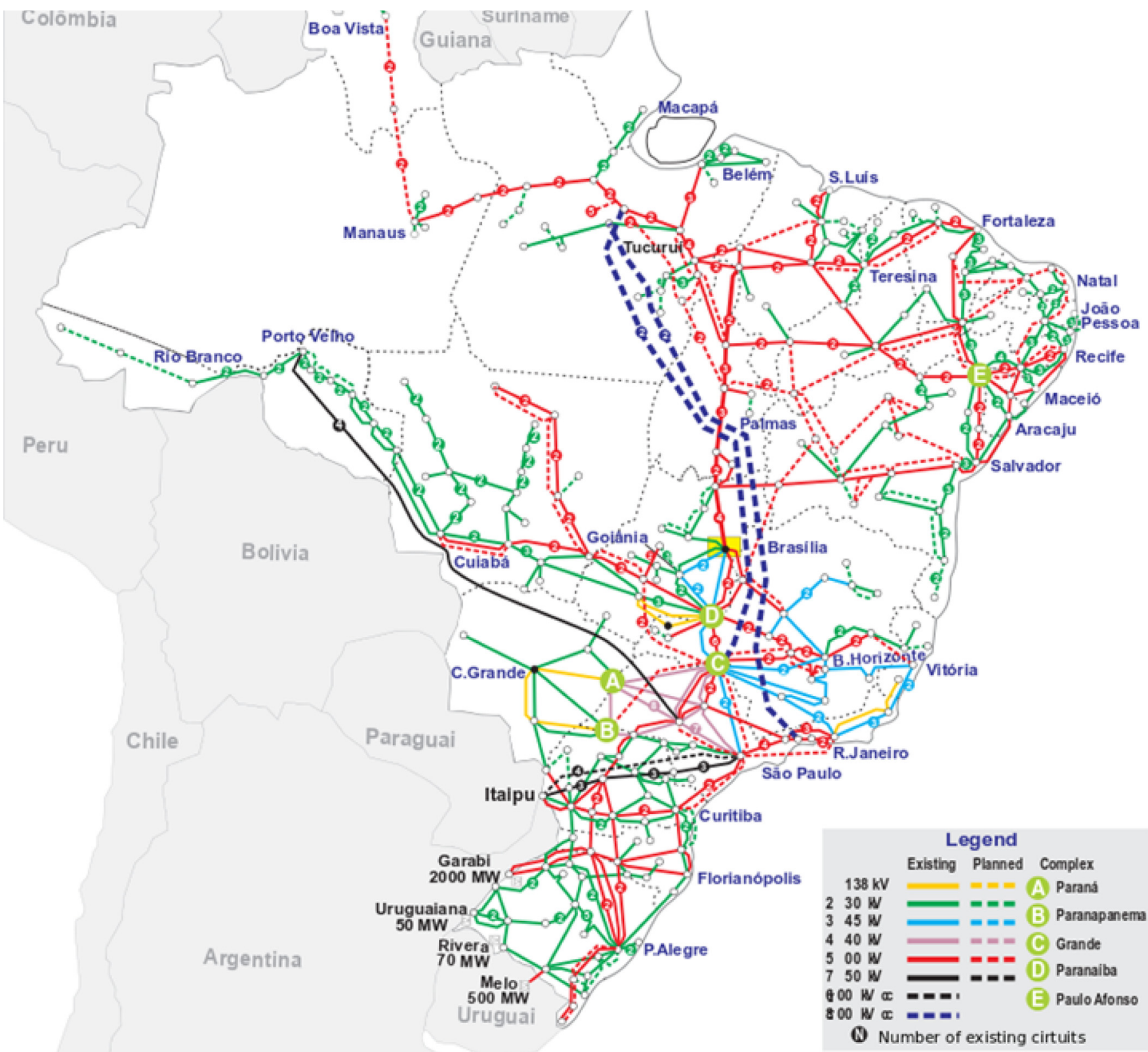

Fig. 7. The national interconnected system. Existing infrastructure and planned expansion 
Table 2

Root definitions of the system.

Customer:

Actor(s):

Transformation

Weltanschhaung Worldview:

Owner:

Environment
Who is the system operated for?

End users: residential, small-business, industries, other mass utilities

Who is the victim or beneficiary of this transformation-system?

The whole economic and production system.

Who will perform the activities involved in the transformation process?

Companies of the generation, transmission, and distribution sectors, regulators and commercialization agents.

What single process will convert the input into the output?

Energy delivery: Generation, Transmission, Distribution, and Commercialization

\section{What makes the transformation worthwhile?}

It is essential to many other industries and activities of the human life.

What is the opinion about the transformation?

There is a consensus that electric utilities need digital evolution. On the other hand, companies do not present resources and capabilities to make changes in the medium term Regulators restricts utilities function by rigid norms of safety and environmental protection that not always drive to facilitate (digitally or not) such changes. Generation and distribution companies have difficulties to access and develop cutting-edge technology in their sectors although they proclaim to be favorable to changes. Customers do not identify value on the availability of electricity in their houses since it is a common and always available service.

Who has the power to say whether the system will be implemented or not? (Who has the authority to make changes happen?) Regulators and government policies.

What are the constraints (restrictions) which may prevent the system from operating? What needs to be known about the conditions that the system operates under?

The main characteristics of the Brazilian electric system are:

- In Brazil, after the 90s, seeking economic efficiency and autonomy, the segments of generation, transmission, and commercialization were separated, being managed and operated by different agents for free competition, where the state has the role of regulating the process. Many agents in generation and commercialization are present. On the other hand, in the transmission and distribution sectors, fewer agents are available, and hence these sectors are considered natural monopolies since it is impossible for two agents to compete in the same concession area.

- Private, public, and mixed capital companies can be agents on all segments.

- Regulation and supervision are the responsibility of ANEEL (National Agency of Electric Energy) which is a governmental company.

- The ANEEL maintains agreements with state regulatory agencies to decentralize part of its activities with supervision, mediation of conflicts, and granting process.

- The ANEEL is also responsible, together with the Mines and Energy Ministry for governmental policies to incentivize sustainable operations and clean energy generation.

- Public or private non-profit companies execute planning tasks as EPE (Energy Research Company), CCEE (Electric Energy Commercialization Chamber) and ONS (National System Operator).

- These planning tasks comprise the system expansion, load distribution, new generation units, among others. The ANEEL partners with these companies.

- ONS (National Operator of Electric System) controls and centralizes the operations of the industry.

- Operations made by the ONS can be defined as the coordination of the National Integrated System (NIS) and planning the operations of some isolated electric systems of the country and receives the supervision and regulation of the ANEEL. ONS develops a series of studies and actions to manage the different sources of energy and the transmission network to guarantee an optimized supply throughout the country, observing the technical standards and reliability criteria established by the ANEEL.

- Transmission and Distribution are regulated on the so-called incentive policy, being remunerated through rates.

- The regulator inputs a constant search for optimum performance, in which companies are penalized based on poor-quality indicators, driving companies to focus on the best use of their assets at the lowest cost, ensuring minimum quality standards, environmental and occupational safety at the lowest risk to people and equipment.

- Interruption and energy quality indicators are used to measure the system reliability.

- New generation developments are free to compete while old large power plants have regulated prices by ANEEL.

Customers can be free (allowed to buy from any provider) or captive (only allowed to buy electricity from the utility in which the customer is connected).

- There is free negotiation between the generator and free customers (hard users)

- Regulated negotiation between generator, transmission, and distribution companies, which provide electricity to captive customers.

- Rates for the generation, transmission, and distribution are accounted separately.

- Prices are determined for each region on concession, instead of a unique flat rate for the entire county.

- Actual contracts have mechanisms to review the economical balance of grantee companies periodically.

- Presence of a large number Interconnected transmission and distribution networks. In this system, higher power losses are held in more distant consumer units. Decentralizing power generation has been targeted by the ANEEL as an option for improving the performance of the distribution (Silva, 2011) 
the efficiency and performance of the power grid by enabling sensors to increase the resilience of the grid (Shrouf et al., 2014).

A key characteristic of smart grids is the access to data. Access to data not only generated in the control and operation of the grid but also generated from the customers through smart meters and sensors. Data is generated in large databases, and the interpretations and analysis are critical for the control and energy dispatch. Therefore, learning from data is essential.

Learning from data is not restricted to learning from customer data and system operation data. In fact, one crucial aspect of the ideal smart electric utility is on a structured asset management system. A structured asset management system can estimate the value assets create by forecasting risks and maintenances based on historical data from assets of individual companies or a set of companies. An asset management system could improve decision making and hence mitigate risks. Therefore, this system can be used as a framework for improved environmental and personal hazard management systems. Hereafter, the electric system of the future needs analytics-based and real-time management systems to help improve the infrastructure for smart grids. As pointed out in (Donnelly, 2018), power quality and reliability are essential, and the current efforts to deploy new technologies for these smart grids are highlighting the importance of information and asset management practices.

The generation, distribution, and transmission environment involve equipment and information traveling on a large network. The generation plant, the transmission and distribution lines, and substations will be connected in a dynamic way, where information flows instantaneously. For example, meteorological data, which is important to predict electrical discharges and faults, will be readily available in the entire electric system. Moreover, meteorological data will help the selection and operation, in real time, of the distributed generation due to the lack of resources, allowing decision-making to connect and operate the system. Data available for electric utilities will comprise all the information of the productive chain, suppliers equipment, governments, climate, and market.

Through machine learning, systems will "learn" with past and present regulatory contexts. For example, the regulatory scenario may influence decision-making in the substitution or exchange of assets. Intelligent systems can help decisions based on historical data and current scenarios and also predict better practices through a possible change in the regulation policies.

The utility of the future will need to modernize its infrastructure and therefore manage resources. This change envisions addressing the high customer expectations of power quality, reliability, and security. Traditional resource management practices were able to reduce risks of inclined-to-failure assets and enhance maintenance plans, but with the great amount of data, new practices are coming ahead. These new practices involve having a great volume of information regarding health indices of equipment and risk scores of procedures in an online way, so to enable reliability, safety, and low environmental risks. With this information, the likelihood of events that can affect the management and replacement of assets will be now accounted and a very much up-to-date risk estimate can be achieved. This information can be used in a feedback process to regulators and important governmental agencies in order to define planning and operation tasks dynamically.

Smart meters will also enable the observation of data from the customer point of view. The better one understands this large data; the better one will know how the system and assets are performing. Data from millions of meters, indicating abnormal operation, for example, would help utilities avoid false alarms and long line inspections. Phasor measurement units (PMUs) should help create a global scenario about the distribution grid since they are smart equipment that measures the system signals uninterrupt- edly. Moreover, utilities could better define where to invest, making smarter decisions on generation sources, decentralized, clean, and environmentally aware generation. It could have better control of the grid by choosing the optimum path to energy dispatch. Investments in distributed and clean generation should rise. Moreover, government and regulators should make policies from to stimulate environmentally aware generation. To do so, transmission and distribution will have to operate in a very efficient way.

Therefore, utilities need to accomplish asset management, information-system development, and data analysis. In this sense, and following the same path as the manufacturing industries in the fourth industrial revolution, the electric system industries need to prepare employees. Staff should be capable of handling and design smart equipment. Electrical engineers will need to be data scientists and have a very large background in statistics. Furthermore, the industry needs should shape the future of engineering education. Major companies should be exchanging these needs with schools and universities.

Finally, the smart utility would work in partnership with customers and regulators to dynamic feedback and change the electric system scenario and guarantee optimal performance, resilience, and efficiency. The population should be aware of the benefits of having a smart grid and should be educated about the importance of correctly using electric power with awareness: from the mitigation of impacts on the environment by making the system more efficient, through the safety of communities and employees.

We could summarize the management practices and requirements a utility should have in an ideal conceptual model of smart utility (Fig. 8).

1 Train data science-driven employees

2 Design and use smart IT systems for information connectivity and analysis

3 Design and use smart asset management systems

4 Feedback regulators with important information

5 Feedback customers with important information and educate people on the importance of a dynamic, resilient, efficient and optimized system.

6 Assess environmental impacts of actual practices

7 Assess regulation constraints and governmental policies regarding environment and asset management.

8 Environmental and personal Hazards management systems

9 Feedback education community on the needs of the smart utility

\subsection{Step 5 - comparing conceptual models with the real world}

By comparing step 2 and step 4 the "systemic world" (ideal situations) can be compared to the real world. Some barriers arise in the real world perspective.

\subsubsection{The first is the cultural aspects}

People often think that electric utility is an old not-prone-totechnology industry since electricity has always been available in their outlets at home or offices. Why should people cope with this transformation? They are usually satisfied with their electricity, so why getting better? Moreover, people have sometimes to invest money. Why invest in smart meters or solar panels? One of the rationales for this kind of thinking is that average Brazilians usually do not have financial education and it is very hard to prove to people that the investment will be paid back. Furthermore, average Brazilian citizens face moments of very high economic and political instabilities. Therefore, being part of a smart utility modernization is not on their priority list. Other utilities, such as gas and sanitation, are focusing more on public education prior to deployment of new technologies. 


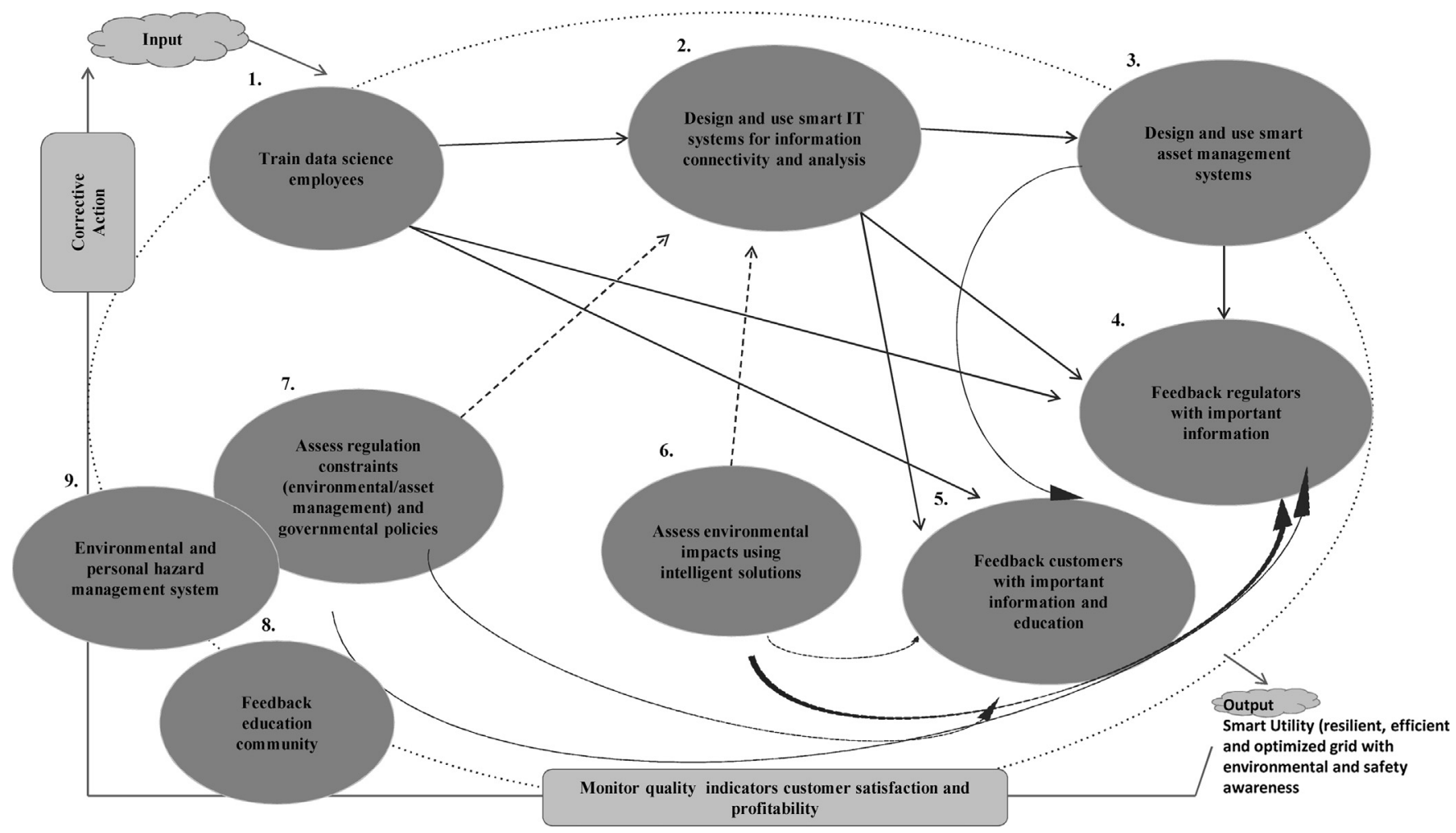

Fig. 8. Conceptual Models of the Smart Electric System Industry.

In the same vein, organizational culture in Brazil is still a problem. Companies must invest tremendous time and effort to explain and educate employees about the importance of having good management practices towards a more efficient, resilient, and optimized industry. This issue again resembles in basic and financial education, which can be filled, partially by in-company training and courses.

Even governmental agencies and regulators should be accepting the changes in order to facilitate the modernization of electric utilities. It is essential, as shown in Fig. 4 that these entities participate actively in the process through a feed-forward and feed-backward relationship with companies in order to update regulations, policies, and environmental constraints. They must realize that when working together, some dumb bureaucracies and policies could be loosened or relaxed. For example, in the Brazilian system, ANEEL has published the MCPSE (Asset Control Manual for the Electric Sector) and created a standard reference code to register assets. Moreover, it imposes the obligation to utilities register the geographical location of each asset (mainly by using geo-referenced information systems (GIS)). In this manual, ANEEL recommends the average maintenance schedule for critical assets. However, ANEEL is not feedbacked from utilities about what is really happening in the real world. Should schedules change? Are different solutions and technologies affecting the way a critical asset responds to the operating process? The feedback loop between utilities and regulators is of paramount importance.

Governmental agencies and players responsible for the system planning should also focus in facilitating the modernization of the grid by holding benefits to those who help to offset energy costs and reduce environmental impacts, from industrial customers to home and small-business customers. In the USA a host of benefits are offered to customers that install solar panels and participate in the distributed generation grid by interconnecting their generation systems. In Brazil, these benefits are almost nonexistent. These investments concern not only economic aspects but also cultural aspects. For example, the Brazilian government has a state policy (Renovabio) that aims to recognize the strategic role of all biofuels in the electricity generation matrix, such as ethanol, biomass, biogas, biodiesel, and promote the participation of these resources in the energy matrix. The policy does not tax the carbon when adding biofuels to fossil-based fuels. However, the policy is still very restricted to power generators and does not consider the whole production chain, from the forestry producer to the final user of the electricity. Therefore, the government should design policies focusing on the complete production chain, contemplating and recognizing the value of all players. For example, benefits would hold to small and medium biomass producers, seedlings producers, and benefits for reforestation should also be assessed, among others.

\subsubsection{The second barrier concerns economic aspects}

In Brazil, state of the art equipment and technologies are very expensive and. Hence, the payback time is very long. This statement is not only valid from the customer point of view but as also from the electric provider point of view. Final products receive one of the biggest tax rates in the world. Products are also taxed to circulate between states (Tax for Movement of Goods and Services - ICMS) and are taxed by federal taxes, such as PIS and COFINS.

The existence of new startups focusing on the intelligent analysis of resources and materials system is also something that is lagging behind. For example, the use of computer vision to inspect equipment and drones to inspect faults in the transmission and distribution lines are not widespread. The Brazilian tax rates do not stimulate entrepreneurs, and entrepreneurship shows itself deficient when compared to other countries.

Another barrier is the government interference in the electricity market and concessions. For some political reasons, sometimes this interference does not address the financial feasibility of the business. In 2013, for example, the Brazilian government would only renew the concessions before the end of the contracts if granted companies decreased rates by $20 \%$ in average. This episode resulted 
in a big political crisis between investors and the Brazilian government.

\subsubsection{The third barrier regards technical and legal aspects}

Even if utilities prepare employees to be data-driven, will it be able to fill in the enormous gap of specialized employees this modern industry requires? Furthermore, are Brazilian industries able to produce competitive equipment in order to lower prices for utilities and consumers? In the same way that smart utilities could help drive manufacturing industries, manufacturing industries can also help drive smart utilities.

Another important aspect of the real world is how to assess regulations and policies in this new proposal of feedback information loop? Energy lawyers will need to understand better legal problems and solutions that will be dynamically changing. Also, research engineers and lawyers will have to speak the same language and understand each other. From this point of view, in Brazil, electric utilities could take lessons learned from the telecommunications industry and other advanced industries for technical, commercial, and legal experience since these industries are regulated as well and have suffered a very radical modernization in the past years.

Assessing environmental impacts is a very difficult aspect as well. Is there an effective way of measuring these impacts? Players should define ways of measuring how new managing actions affect the environment. For example, how the life cycle optimization of a power transformer quantitatively impacts the environment? How do smart meters impact the reduction of pollutant generation? Accessing this information is essential to the new framework on process safety and environmental protection in the smart utility paradigm.

\subsection{Step 6 - systemic desirable changes}

At this point, we propose and discuss some actions and changes that should facilitate utilities to grow within the industry 4.0 scenario, and verify if they are feasible, as well as desirable. To do so, one must consider whether the changes will be accepted and incorporated into the cultural, economic, and financial feasibility context (Venturi et al., 2006). Checkland (1981) highlights three types of changes that may occur: structural, procedural, and of attitudes.

Three barriers were identified as cultural, economic, and technical aspects, as described in Table 3.

\subsection{Step 7 - actions to improve the problem situation}

To thrive in the industry 4.0 scenario, electric utilities need to implement changes in technical, economic and cultural aspects. Changes can be summarized in:

- better policies to regulate the relationship with companies, which would enable feedback loops between members of the value chain

- partnerships to promote and fill in the gap of technical education for the workforce

- partnerships to create value and educate the population and the workforce on the benefits of this industrial modernization, per passing some cultural barriers.

What can be seen, in general terms, is a closed and static industry system. By using systemic thinking, we can consider the electric system industry as a closed system, since its constituting elements can not learn from the environment. The role of regulation turns the system rigid even though free competition exists in some segments of the electric sector. The lack of dynamism comes from the absence of retrofitting between all stakeholders which paralyzes the system and do not allow its evolution. Educational gap and bureaucratic business market are genuineness antecedents of a low-level performance on innovation. We shall stress that it is imperative to the electric system to be more efficient and smarter, with fewer losses, so that more focus could be given to alternative and clean power generation sources since these sources generally have a smaller scale of assessment. A great focus is on sustainable generation, but the whole system, including transmission and distribution, must be efficient for that to be possible.

Companies must detail the organizational capabilities they need to improve in all business processes, for example, an agile IT infrastructure and team and expert teams in data analytics. Collaboration with universities, startups, industry, and scientific organizations help accelerate the innovation and create an organizational culture towards smart production.

These capabilities need to be dynamic; a capability is considered dynamic when it enhances the ability of a firm to make decisions, solve problems, identify opportunities and threats, and modify existing resources (Barreto, 2009; Liboni-Amui et al., 2017). Helfat (2007, p. 4) define dynamic capabilities as "the capacity of an organization to purposefully create, extend, and modify its resource base".

The organizational dynamic capabilities facilitate the reconfiguration and changes towards a new smart production industry, aligned to the new industrial paradigm. In the other way around, this new paradigm of industry 4.0 brings profound modifications in the organizations, by changing management practices and developing continuously new capabilities that can maintain these innovations and changes.

It is clear that environmental protection and process safety are goals within the fourth industrial revolution, and that stakeholders, from the electric utility industry (from the generation company to the final customers) need to target. Having these important goals will help companies develop important dynamic capabilities - new policies to enable innovation, bureaucracy reduction, and investments in education - which will help raise innovation towards the requirements of industry 4.0. As a consequence, a smart utility would sure result in less environmental impact and less hazardous operations.

\section{Conclusions}

We have built a landscape of the challenges brought by the industry 4.0 paradigm in the electric system industry in Brazil, focusing on the topic of environmental protection and process safety. Since essential public services are dependent on electricity to provide human safety and the occurrence of electric faults, interruptions, or diminished quality of the electricity can lead to chaotic consequences in the environment, it is clear that utilities must keep up to changes in order to become more sustainable. Moreover, a smarter utility could better plan investments on different energy generation systems which directly impacts the environment. The benefits from this transformation are straightforward: the increase in the electricity quality, reduction of the electricity cost, better maintenance service, more significant environmental awareness in the management of distributed generation, and safer environments for employees and users.

The electric system context was detailed and it is noticeable that the sector is lagging in modernization, mainly because of barriers in three different spheres: cultural, economic, and technical aspects. Therefore, big challenges are expected, and the goal of modernization will only be achieved if the attitude towards a more modern utility, either from customers and the industry itself, becomes unrestricted.

More specifically, the results from the SSM have exposed that the system is somewhat static and closed, mainly because of restric- 
Table 3

Desirable changes in the electric utility system.

\begin{tabular}{|c|c|c|c|}
\hline Changes Barriers & Structural Changes & Process Changes & Attitudes Change \\
\hline 1-Cultural & $\begin{array}{l}\text { Educate people to value the availability of } \\
\text { electricity and technology. Awareness } \\
\text { programs that could provide simple } \\
\text { information about the investments in } \\
\text { technology that utilities make. Convince } \\
\text { people of the importance of the balanced } \\
\text { offer among the value chain and the risks } \\
\text { of explosions, environmental damages, and }\end{array}$ & $\begin{array}{l}\text { Organizational culture should move } \\
\text { towards reducing government } \\
\text { dependence. Concessions and regulators } \\
\text { are mandatory. However, investments and } \\
\text { new opportunities can arise from } \\
\text { international markets. Optimizing } \\
\text { performance indicators on their own, not } \\
\text { only linked to regulation requirements but }\end{array}$ & $\begin{array}{l}\text { The capacity of thinking of a new model of } \\
\text { bureaucracy in the electric system. It } \\
\text { means that norms and regulations from } \\
\text { top-down, from agency to companies, } \\
\text { should obey a certain order, respecting } \\
\text { long-range contracts and understanding } \\
\text { that helping the industry is a win-win } \\
\text { process to all society. }\end{array}$ \\
\hline
\end{tabular}

2 - Economic By far the most difficult barrier. Economic structure in Brazil is unstable and deeply dependent on the actual political ideology. The mix of responsibilities between the Ministry of Mines and Energy and ANEEL could be discussed in order to clarify roles in the industry 4.0. A fiscal reform should also improve the business market.

\section{3 - Technical (workforce)}

Large investments in IT education in a nation-wide effort. Brazil has a capillary network of Federal institutions that could offer partial time data-analytics courses for young professionals.

4 - Technical (environmental impact)
Regarding the rigid regulation of the federal agencies, we propose a top-down initiative of composing a federal committee to discuss asset management. Modernization of norms and regulations to synchronize equipment maintenance guidelines instead of fixed schedule proceedings. Consolidating the supply chain management could be possible through IoT and interconnection of members activities. also to the performance of the overall organization.

Incentives through taxes reduction to help companies afford the purchase and upgrade of new expensive equipment. BNDES (Brazilian National Bank for Development) could improve specific innovation-related credit lines for utility companies. Cost incentives like FINEP

(Federal Innovation Agency) could also focus a specific fund to enable innovation inside companies.

We propose the enhancement of partnerships with private educational institutions. For top managers, companies can pursue a short-range association with MBA courses specific to IT strategic management related areas.

Discussions on National policies to improve the business market of the industry as a whole, and especially about managing new criteria for asset management and its environmenta impacts. Incentives to companies that develop intelligent environmental and hazard management systems. The government should create actions and benefits for producers in order to boost the use of biofuels, such as biomass. As suggested in the Bioenergy report from the State of Sao Paulo, the government must still create policies to accelerate the use of the full Brazilian potential in renewables.
Entrepreneurship and innovation ecosystem should be stimulated. The partnership between engineering faculties, start-ups and companies, with the participation of angel and incubator investments could foment innovation.

Openness to partnerships in order to develop customized education programs like corporate universities that could qualify the engineers adding managerial and data skills.

The federal committee could work against the lack of feedback that companies suffer when restricting them relevant information. Therefore, promoting forums and regular reports of critical information is paramount. tive regulations and the low-value given by end users. Within this context, important management gaps were revealed and had enabled us to assess the organizational capabilities this industry will need to thrive in the modern business process and identify new management practices that could contribute to advancing the industry 4.0 in the electric utilities. Thriving in the new modernization context means developing appropriate dynamic capabilities, such as creating new policies to enable network innovation, reducing the bureaucracy, and searching for fulfillment of the workforce gap. These new management practices (Fig. 6) and capabilities should be developed and information between the stakeholders, in which the regulator and customers are accounted for, should be exchanged in a feedback process in order to make the modernization process dynamic.

No short-term changes are expected in this industry if players, which are composed of users, employees, and managers, do not actively participate in the modernization process. The main shortterm challenges are to overcome existing practices and beliefs such as organizational culture and more investments in educating the final users of the importance of a smart utility to enable companies to adapt and innovate. Long-term challenges comprise training data science-driven employees, designing better IT systems, asset management systems, personal hazard systems, assessing regulatory constraints on asset management and environmental policies, and feeding back information transparently to regulators. Yet, regulators and governmental agencies linked to the electric system industry should also prioritize the feedback loop and understand the importance of the modernization.

The limitations of this study are the lack of quantitative data about management practices and especially performance indicators regarding safety and environmental impacts. Future studies may concentrate on standardizing a management learning framework for the electric system industries, creating a common platform that allows data sharing and collaborative work among the members of the supply chain. This platform would then result in data that should point out the enhancements of these new management practices towards a more sustainable, safe and environmentally aware utility. In addition, next investigations could explore the learning experience of case studies in this sector, identifying key dynamic capabilities linked to knowledge, asset management, and circular economy.

\section{References}

Baccarelli, E., Naranjo, P.G.V., Scarpiniti, M., Shojafar, M., Abawajy, J.H., 2017. Fog of everything: energy-efficient networked computing architectures, research challenges and a case study. IEEE Access 5, 9882-9910.

Bakkari, M., Khatory, A., 2017. Industry 4.0: Strategy for more sustainable industrial development in smes. Paper presented at the Proceedings of the International Conference on Industrial Engineering and Operations Management, 1693-1701.

Barreto, I., 2009. Dynamic capabilities: a review of past research and an agenda for the future. J. Manag. 36 (1), 256-280.

Cezarino, L.O., Liboni, L.B., Oliveira, M.F., Caldana, A.C.F., 2016. Soft systems methodology and interdisciplinarity in management education. Syst. Res. 33, 278-288, http://dx.doi.org/10.1002/sres.2383. 
Checkland, P. (1981). Systems Thinking, Systems Practice. John Wiley \& Sons, Chichester. REN21. (2016). Renewables 2016 Global Status Report. Renewable Energy Policy Network for the 21st Century. Paris: REN21 Secretariat. ISBN 978-39818107-0-7.

De Rademaeker, E., Suter, G., Pasman, H.J., Fabiano, B., 2014. A review of the past, present and future of the european loss prevention and safety promotion in the process industries. Process Safety Environ. Protect. 92 (4), 280-291, http://dx. doi.org/10.1016/j.psep.2014.03.007.

Donnelly, T., 2018. *Smart Asset Management. T\&D World Magazine, Available at http://www.tdworld.com/asset-management-service/smart-assetmanagement.

EPA United States Environmental Protection Agency, 2017. About-us-ElectricitySystem-and-its-Impact-Environment, Available at https://www.epa.gov/ energy/about-us-electricity-system-and-its-impact-environment.

Energética Empresa de Pesquisa, 2012. Projeção da Demanda de Energia Elétrica: para os próximos 10 anos (2013-2022). Ministério de Minas e Energia, In Serie: Estudos de Demanda de Energia-Nota Técnica DEA, 22, 12 (in Portuguese).

Feeders, R.D.T., 1991. IEEE distribution planning working group report. IEEE Trans. Power Syst. 6 (3), 975-985

Ferdous, R., Khan, F., Sadiq, R., Amyotte, P., Veitch, B., 2013. Analyzing system safety and risks under uncertainty using a bow-tie diagram: an innovative approach. Process Saf. Environ. Protect. 91 (1), 1-18.

Gabriel, M., Pessel, E., 2016. Industry 4. 0 and sustainability impacts: critical discussion of sustainability aspects with a special focus on future of work and ecological consequences. Ann. Fac. Eng. Hunedoara Int. J. Eng 1(16), 131-136.

Geissbauer, R., Vedso, J., Schrauf, S., 2016. Industry 4.0: Building the Digital Enterprise (Retrieved from PwC Website: https://www.pwc.com/gx/en/industries/ industries-4.0/landing-page/industry-4.0-building-your-digital-enterpriseapril-2016.pdf.

Geissdoerfer, M., Savaget, P., Bocken, N.M., Hultink, E.J., 2017. The circular economy-a new sustainability paradigm? J. Clean. Prod. 143, 757-768

Georgiou, I., 2008. Making decisions in the absence of clear facts. Eur. J. Oper. Res. 185 (1), 299-321.

Glavič, P., Lukman, R., 2007. Review of sustainability terms and their definitions. J. Clean. Prod. 15 (18), 1875-1885.

Gregori, F., Papetti, A., Pandolfi, M., Peruzzini, M., Germani, M., 2017. Digital manufacturing systems: a framework to improve social sustainability of a production site. Procedia CIRP 63, 436-442.

Grzeidak, E., Cormane, J., Filho, A.F., Nascimento, F., 2011. Qualidade da energia elétrica no contexto de smart grid. Conferência Brasileira sobre Qualidade da Energia Elétrica (in Portuguese).

Helfat, C.E., 2007. Dynamic Capabilities: Understanding Strategic Change in Organizations. Blackwell, Malden.

Herrmann, C., Schmidt, C., Kurle, D., Blume, S., Thiede, S., 2014. Sustainability in manufacturing and factories of the future. Int. J. Precis. Eng. Manuf.-Green Technol. 1 (4), 283-292.

Kang, H.S., Lee, J.Y., Choi, S., Kim, H., Park, J.H., Son, J.Y., et al., 2016. Smart manufacturing: past research, present findings, and future directions. Int. J. Precis. Eng. Manuf-Green Technol. 3 (1),111-128.

Kiel, D., Müller, J.M., Arnold, C., Voigt, K.I., 2017. Sustainable industrial value cre ation: benefits and challenges of industry 4.0. Int. J. Innovation Manage. 21 (08) 1740015.

Kleindorfer, P.R., Singhal, K., Wassenhove, L.N., 2005. Sustainable operations management. Product. Oper. Manage. 14 (4), 482-492.

Kleineidam, G., Schmid, L.J., Krasser, M., Koch, B., 2017. Critical infrastructures-cyber security requirements from a utility's perspective. [Kritische Infrastrukturen - Sicherheitsanforderungen an die Informations-und Kommunikationstechnik aus Sicht eines Versorgungsunternehmens]. Elektrotechnik Und Informationstechnik 134 (1), 3-13, http://dx.doi.org/10.1007/s00502-017-0471-9.

Lee, J., Bagheri, B., Kao, H.A., 2014. Recent advances and trends of cyber-physical systems and big data analytics in industrial informatics. International Proceeding of Int Conference on Industrial Informatics (INDIN), 1-6.

Li, X., Li, D., Wan, J., Vasilakos, A.V., Lai, C.F., Wang, S., 2017. A review of industrial wireless networks in the context of industry 4.0. Wireless Netw. 23 (1), 23-41.

Liboni, L.B., Cezarino, L., Caldana, A.C.F., Donaires, O.S., 2015. Diagnosing failure in an organizational strategic alliance for new product development. Syst. Res. 32, 721-734, http://dx.doi.org/10.1002/sres.2269.

Liboni-Amui, L.B.L., Jabbour, C.J.C., de Sousa Jabbour, A.B.L., Kannan, D., 2017. Sustainability as a dynamic organizational capability: a systematic review and a future agenda toward a sustainable transition. J. Clean Prod. 142, 308-322.

Markowski, A.S., Mannan, M.S., Bigoszewska, A., 2009. Fuzzy logic for process safety analysis. J. Loss Prevent. Process Ind. 22 (6), 695-702, http://dx.doi.org/10.1016 j.jlp.2008.11.011.

Müller, J., Dotzauer, V., Voigt, K.I., 2017. Industry 4.0 and Its Impact on Reshoring Decisions of German Manufacturing Enterprises. In Supply Management Research. Springer Gabler, Wiesbaden, pp. 165-179.

Müller, J.M., Kiel, D., Voigt, K.I., 2018. What drives the implementation of industry 4.0? The role of opportunities and challenges in the context of sustainability. Sustainability 10 (1), 247

Marques, M., Agostinho, C., Zacharewicz, G., Jardim-Gonçalves, R., 2017. Decentralized decision support for intelligent manufacturing in Industry 4.0. J. Ambient Intell. Smart Environ. 9 (3), 299-313.
Monostori, L., Kádár, B., Bauernhansl, T., Kondoh, S., Kumara, S., Reinhart, G., et al., 2016. Cyber-physical systems in manufacturing. CIRP Ann. 65 (2), 621-641.

Mourtzis, D., Vlachou, E., Xanthopoulos, N., Givehchi, M., Wang, L., 2016. Cloud-based adaptive process planning considering availability and capabilities of machine tools. J. Manuf. Syst. 39, 1-8.

Murray, A., Skene, K., Haynes, K., 2017. The circular economy: an interdisciplinary exploration of the concept and application in a global context. J. Bus. Ethics 140 (3), 369-380.

Oesterreich, T.D., Teuteberg, F., 2016. Understanding the implications of digitisation and automation in the context of Industry 4.0: a triangulation approach and elements of a research agenda for the construction industry. Comput. Ind. 83, $121-139$

Oettmeier, K., Hofmann, E., 2017. Additive manufacturing technology adoption: an empirical analysis of general and supply chain-related determinants. J. Bus. Econ. 87 (1), 97-124.

Peukert, B., Benecke, S., Clavell, J., Neugebauer, S., Nissen, N.F., Uhlmann, E., et al., 2015. Addressing sustainability and flexibility in manufacturing via smart modular machine tool frames to support sustainable value creation. Procedia CIRP 29, 514-519.

Prause, G., Atari, S., 2017. On Sustainable Production Networks for Industry 4.0

Ralff-Douglas, K. Zafar, M. (2015). Electric Utility Business and Regulatory Models. California Public Utilities Commission Policy \& Planning Division Available at: http://www.cpuc.ca.gov/uploadedFiles/CPUC_Public_Website/ Content/About_Us/Organization/Divisions/Policy_and_Planning/PPD_Work/ PPDElectricUtilityBusinessModels.pdf.

Sarkis, J., Zhu, Q., 2018. Environmental sustainability and production: Taking the road less travelled. Int.J. Prod. Res. 56(1-2), 743-759, http://dx.doi.org/10.1080/ 00207543.2017 .1365182

Schwab, K., 2017. The Fourth Industrial Revolution. Crown Business.

Selltiz, C., 1974. Métodos de pesquisa nas relações sociais. EPU.

Seuring, S., Müller, M., 2008. From a literature review to a conceptual framework for sustainable supply chain management. J. Clean. Prod. 16 (15), 1699-1710.

Shim, S.O., Park, K., Choi, S., 2017. Innovative production scheduling with customer satisfaction based measurement for the sustainability of manufacturing firms. Sustainability 9 (12), 2249.

Shrouf, F., Ordieres, J., Miragliotta, G., 2014. Smart factories in Industry 4.0: A review of the concept and of energy management approached in production based on the Internet of Things paradigm. In: Industrial Engineering and Engineering Management (IEEM), 2014 IEEE International Conference, IEEE, pp. 697-701 (December)

Silva, P., 2011. Análise do impacto regulatório na dificuldade de implantação de projetos de cogeração a partir da biomassa da cana em mato grosso do sul. In Congresso Brasileiro de Regulação, vol. 7 (in Portuguese).

Stock, T., Seliger, G., 2016. Opportunities of sustainable manufacturing in industry 4.0. Procedia Cirp 40, 536-541.

Strandhagen, J.O., Vallandingham, L.R., Fragapane, G., Strandhagen, J.W., Stangeland, A.B.H., Sharma, N., 2017a. Logistics 4.0 and emerging sustainable business models. Adv. Manuf. 5 (4), 359-369.

Strandhagen, J., Alfnes, E., Strandhagen, J.O., Vallandingham, L., 2017b. The fit of Industry 4.0 applications in manufacturing logistics: a multiple case study. Adv. Manuf. 5, http://dx.doi.org/10.1007/s40436-017-0200-y.

Venturi, G., Troost, J., Jokela, T., 2006. People, organizations, and processes: An inquiry into the adoption of user-centered design in industry. Int J. Human-Computer Interact. 21 (2), 219-238, http://dx.doi.org/10.1207 s15327590ijhc2102_6.

Vrancken, K.C., 2018. Moving towards a digitally powered circular economy: conclusions of the gstic circular economy track. G-STIC -Global Science, Technology \& Innovation Conference Series, Available at: http://web.unep.org/ietc/sites unep.org.ietc/file/G-STIC_Circular_Economy_Outline\%20and\%20Conclusions_ final-\%20171025.pdf.2017.

Waibel, M.W., Steenkamp, L.P., Moloko, N., Oosthuizen, G.A., 2017. Investigating the effects of smart production systems on sustainability elements. Procedia Manuf 8, 731-737.

Wan, J., Tang, S., Shu, Z., Li, D., Wang, S., Imran, M., Vasilakos, A.V., 2016. Softwaredefined industrial internet of things in the context of industry 4.0. IEEE Sens. J. 16 (20), 7373-7380

Wang, S., Wan, J., Li, D., Zhang, C., 2016. Implementing smart factory of industrie 4.0 an outlook. Int. J. Distrib. Sensor Netw. 12 (1), 3159805

Weissman, S., 2011. Public Policy and Those Pesky Smart Meters. Berkeley Blog, Available at http://blogs.berkeley.edu/2011/03/14/public-policy-andthose-pesky-smart-meters.

Young, R., McCue, J., Grant, C., 2016. The Power Is On: How IoT Technology Is Driving Energy Innovation. Deloitte Insights, Available at https://www2. deloitte.com/ insights/us/en/focus/internet-of-things/iot-in-electric-power-industry.html.

Zexian, Y., Xuhui, Y., 2010. A revolution in the field of systems thinking - a review of checkland's system thinking. Syst. Res. Behav. Sci. 27 (2), 140-155.

Zheng, P., Sang, Z., Zhong, R.Y., Liu, Y., Liu, C., Mubarok, K., et al., 2018. Smart manufacturing systems for Industry 4.0: conceptual framework, scenarios, and future perspectives. Front. Mech. Eng., 1-14.

Zhong, R.Y., Xu, X., Klotz, E., Newman, S.T., 2017. Intelligent manufacturing in the context of industry 4.0: a review. Engineering 3 (5), 616-630. 